This is the peer reviewed version of the following article: Ramdharry, Gita, Reilly-O'Donnell, Louise, Grant, Robert and Reilly, Mary M (2018) Frequency and circumstances of falls for people with Charcot-Marie-Tooth disease : a cross sectional survey. Physiotherapy Research International, 23(2), e1702., which has been published in final form at https://dx.doi.org/10.1002/pri.1702. This article may be used for non-commercial purposes in accordance with Wiley Terms and Conditions for Self-Archiving. 
Physiotherapy Research International: Manuscript accepted 14/11/2017

\title{
Frequency and circumstances of falls for people with Charcot-Marie-Tooth disease: a cross sectional survey
}

\begin{abstract}
Objective: People with Charcot Marie Tooth (CMT) disease may be at risk of falls due to distal muscle weakness and sensory impairment. We aimed to understand the frequency of falls in a cohort, where they occurred, injury and to what people attributed the possible cause.
\end{abstract}

Design: A cross sectional survey design was used. It was sent by post to ascertain the frequency of falls and near falls, plus the circumstances of the last three falls events they could recall.

Setting: The survey was administered to 252 people with CMT who were patients at a specialist neuromuscular centre.

Participants: People were approached who had a clinical diagnosis by a neuromuscular specialist neurologist.

Interventions: Not applicable

Main Outcome Measure: The Falls Event Questionnaire

Results: Responses were received from 107 people with CMT. Falls and near falls were reported by $86 \%$ of survey respondents. The majority of falls occurred at home, and muscular weakness appeared to be blamed the most, with participants describing tripping due to foot drop or joints giving way. A similar pattern was observed for near falls, but they tended to be more frequent. Moderate and major injuries were relatively rare, with the majority of falls resulting in scrapes and bruises, or the faller feeling shaken by the experience. 
Physiotherapy Research International: Manuscript accepted 14/11/2017

Discussion: The impact of falls is far reaching, in terms of injury risk and the consequences of the fear of falling. Interventions to improve balance and reduce falls are an important rehabilitation focus for people with CMT.

\section{Implications for physiotherapy practice:}

- The results of this study highlight that falls and near falls are frequent events in a cohort of people with Charcot-Marie-Tooth disease

- The results give further information on the circumstances and causes of falls. This new knowledge can inform assessment of falls risk, specific interventions and falls management approaches

Key words: Balance; Charcot-Marie-Tooth disease; falls 
Physiotherapy Research International: Manuscript accepted 14/11/2017

\section{Introduction}

Charcot-Marie-Tooth disease (CMT) is the most common inherited neuromuscular disorder with an incidence of 1 in 2500 , though this varies among reported epidemiology studies between 9.7/100,000 to 82.3/100,000 (Barreto et al., 2016). CMT is an umbrella term for over 80 different genetic causes of peripheral neuropathy. There is variation in the inheritance and pathology of the different causes, so CMT is categorized into types: CMT type 1 has dominant inheritance and is a demyelinating disease; CMT type 2 has a dominant inheritance and affects the nerve axons; CMT type $\mathrm{X}$ has an X-linked inheritance; CMT type 4 has a recessive inheritance; distal hereditary neuropathy affects the axons and has a motor predominance; hereditary sensory neuropathy affects the axons and has a sensory predominance, though some types also present with motor impairment; intermediate CMT has a mixture of demyelinating and axonal pathological features. Despite the genetic heterogeneity, as a group people with CMT typically develop a slow progressive length dependent neuropathy that manifests initially with distal lower motor neuron weakness and sensory loss (Rossor, Evans, \& Reilly, 2015).

Falls and balance impairments are reported in the clinics as problematic for people with CMT, and only one study to date has explored this issue in adults. Eichinger et al. (Eichinger, Odrzywolski, Sowden, \& Herrmann, 2016) reviewed case notes of 28 people attending CMT clinics who received a comprehensive balance assessment. Correlations were found between balance confidence, reported falls and functional tests. A higher frequency of falls has also been reported in children with CMT(Burns, Ryan, \& Ouvrier, 2009). 
This study addressed the frequency of falls in a larger cohort, and explored the circumstances of the falls themselves. The primary aim was to ascertain the frequency of falls to the ground and near falls. The secondary aim was to collect descriptive data about where the events occurred, what participants were doing, and why they think they happened.

\section{Method}

We used a cross sectional postal survey design that included the Falls Events Questionnaire (FEQ), a tool that asks people to recall the situation of their last three falls and last three near falls. (Ashburn, Stack, Ballinger, Fazakarley, \& Fitton, 2008; Hiscock et al., 2014; Hyndman, Ashburn, \& Stack, 2002; Stack \& Ashburn, 1999). The original FEQ is administered by interview, so a paper version was piloted on a small sample of people with CMT and altered so participants could estimate falls frequency from a range of categories. Participants were asked if they had fallen to the ground in the last year. If they answered no, they were forwarded to the section on near falls. Details of the circumstances of the fall or near fall were requested (table 1). We successfully used the same questionnaire on another neuromuscular cohort (Hiscock et al., 2014). The study methods and amended questionnaire were approved by the Central London Research Ethics Committee. The questionnaire was posted to 252 people with clinically confirmed CMT on the database of the clinical service at the Queen Square Centre for Neuromuscular Diseases, Queen Square in London. A three-month window was allowed for responses and follow up letters were sent after two weeks of the delivery of the survey. 
Analysis: The proportion of participants was calculated within each falls frequency category and expressed as a percentage of total respondents. Near misses were analysed in the same way. Demographic differences between the responders and non-responders to the surveys were explored used t-tests and Mann-Whitney $\mathrm{U}$, depending on data type. Kendall's-tau correlations investigated if there were relationship between frequency of falls and key factors: age, sex and type of CMT.

Descriptive data was collated and coded. The numbers of participants describing a phenomenon were categorized independently then agreed by two researchers (and summed to give an estimation of the frequency of the experience.

\section{Results}

Of the 252 questionnaires administered, 107 were returned. All respondents responded to the first section of the questionnaire regarding frequency of falls but only 282 of a possible 324 falls events were described in the more detailed questions. Completed answers only are presented in this section and will account for any discrepancy in total percentages.

There was a significant difference in age of responders versus non-responders $(\mathrm{t}=-$ 3.46, $\mathrm{p}=0.001$ ) but not in sex or CMT type (table 1 ).

Frequency of falls and near falls: The percentage of people reporting falls was $86 \%$ for the responders ( $n=107$ ) with $95 \%$ confidence interval $(\mathrm{Cl}) 78.5 \%$ to $91.6 \%$, and if 
there is an assumption that the non-responders did not fall as a worst-case scenario, $35.3 \%$ of all surveyed reported falls $(n=252)$. Just under a third of respondents reported falling once a month (29.9\%; 95\% Cl 22.4-39.2). Most respondents did not fall more than once a month, but nearly a fifth fell at least weekly $(14 \%$; $95 \%$ CI $7.5-$ 20.6) (figure 1a). Near falls were reported by $86 \%(95 \% \mathrm{Cl} 78.5-92.5)$ of responders and were more frequent than actual falls with the majority occurring weekly $(30 \%$; $95 \%$ Cl 19.6-36.4) or monthly (27\%; 95\% Cl 16.8 - 33.6) (figure $2 a)$.

Effect of age, sex and CMT type: There was a weak positive correlation between age and the falls frequency categories $(r=0.147, P=0.04)$. No relationship was observed between falls frequency and $\operatorname{sex}(r=-0.06, P=0.49)$ or type of CMT $(r=0.029$, $P=0.72)$.

Circumstances of falls: Falls happened most of often indoors, mainly at home (36.6\%). Falls outdoors were frequent (28.6\%) with some respondents identifying uneven ground as a specific cause (13.9\%). Falls when negotiating stairs happened to a smaller proportion (4.6\%) and a minority of respondents were unable to recall $(2.5 \%)$ (figure $1 b)$.

Many falls occurred when walking (51.8\%). Other less common scenarios were negotiating stairs, transfers, standing, reaching, carrying loads, performing activities of daily living and external perturbations (figure 1c).

The perceived reason for falls was variable. Muscular weakness was reported as the possible cause in nearly a quarter of falls events (23.9\%) with descriptions of legs 
failing to move sufficiently, foot drop, and joints giving way. Trips were specifically blamed for over a fifth of falls (22.7\%) and others felt they were due to slippery or uneven ground (18.9\%). A general loss of balance or specific ankle instability was perceived to be a cause in a quarter. Other less frequent perceived causes were fatigue, lack of sensation, reduced concentration, a failure of footwear/external support or a fall due to an external perturbation (figure 1d).

Nearly half of falls resulted in minor injuries (47.5\%) e.g. bruises, and no injuries in nearly a third (30.3\%). Moderate injuries, such as sprains, were less frequent (13.1\%) and major injuries, such as fractures, were rare (2.7\%). Psychological effects, such as feeling shaken, were also described (3.6\%).

Circumstances of near falls: When most near falls occurred, respondents were walking (63.4\%). Near falls also happened when negotiating steps (8\%) and when undertaking other physical activities such as golf or hiking (8\%). Less frequently, near falls occurred during transfers $(4.5 \%)$, when standing $(4 \%)$, when reaching for objects (2.7\%), when carrying loads (2.7\%) and during daily activities such as cooking $(0.9 \%)$.

Participants reported that trips were the most common possible cause, accounting for $26 \%$ of near falls. Muscular weakness was blamed for $23.8 \%$ of events, often due to ankles and knees giving way. A general loss of balance was reported to cause $21.5 \%$ of near falls and slippery or rough terrain $16.6 \%$. Other less common reported causes were fatigue $(7.6 \%)$, reduced concentration $(5.4 \%)$, sensory loss $(3.1 \%)$ and poor footwear (1.3\%). Four percent of respondents could not recall a specific cause. 
Respondents also recounted how they avoided falling (figure $2 b$ ) with the majority holding onto a stable surface (55.8\%), regaining balance themselves or with a walking aid (27.9\%) and by holding another person (10\%). Others were able to control a fall to the ground (3.3\%) and a small number could not recall (4.2\%).

\section{Discussion}

Participants of this study reported frequent falls and near misses, identifying weakness as being the main cause, with either joints giving way or tripping due to drop foot. Uneven ground was not always implicated as a contributor to a fall implying that foot drop is a factor regardless of environment. Stair climbing was considered separately to uneven ground, as it is a more physically demanding ambulation activity than walking on the level, requiring different kinematics and presenting greater risk of injury (Handsaker et al., 2016).

Tripping and muscular weakness may have the same cause, but here we represented the perceptions of the respondents. Interestingly sensory loss was only specifically identified by a few considering this has been suggested to be a key contributor to balance impairment with greater visual dependence (van der Linden, van der Linden, Hendricks, van Engelen, \& Geurts, 2010); but this has been refuted by other studies implicating distal muscle weakness as a key contributor to postural stability (Nardone et al., 2006; Tozza et al., 2016). These are all laboratory based studies, however, and did not explore the relationship of impairments, balance performance and falls. In other neuromuscular diseases, a study of mixed neuromuscular conditions identified weakness as a cause by comparing a falls 
history questionnaire to clinical presentation (Pieterse et al., 2006). Falls in people with myotonic dystrophy were found to correlate between distal lower limb weakness and falls/stumble frequency perhaps due to a loss of "pillar support" with minor, sudden perturbations in stance (Wiles et al., 2006).

When investigating falls risk, all aspects of postural control should be considered. Static posturography may not be helpful in isolation as people fall less when simply standing. This survey suggests that failure to recover from a trip is a common perceived cause of falls, and may indicate a delayed reactive strategy. This could be due to slowed rate of force production in weakened muscles or sensory dysfunction, as seen in other peripheral neuropathies and older people (Handsaker et al., 2016; Kim \& Robinson, 2006). A study by Nardone et al. (Nardone, Grasso, \& Schieppati, 2006) explored reactive strategies in people with peripheral neuropathy, relating them to postural control but not to falls. Proactive balance strategies, however, have not been well explored to date.

The relative impact of clinical presentation on balance and falls requires further investigation with more dynamic test situations than have been used to date. This will help to target rehabilitation interventions to the main risk factors, aiming to reduce falls.

In this study, response bias is probable and people may only have responded if falls are a problem to them. We can state from our results that between $35 \%$ and $83 \%$ of 
our sampling frame reported falls in view of the risk of response bias. The study by Eichinger et al. (1) reported falls in $50 \%$ of their retrospective cohort. This would fit within our estimate range, but with cautious comparison as the data is from a small sample of 28 individuals. The lowest estimation of $35 \%$ from our survey data is likely to be overly conservative as it will assume that non-responders did not fall, which is unlikely. Despite this, the lower estimate of $35 \%$ is still a higher than expected proportion of people falling considering other demographic factors such as age. A study of 1497 healthy community dwelling adults in the USA reported at least one fall in a two year period in $18 \%$ of young adults, $21 \%$ of middle-aged, and $35 \%$ of older adults (Talbot, Musiol, Witham, \& Metter, 2005). This prevalence range of $18-35 \%$ is much lower than the range reported from this sample of people with CMT with a similar age range $(17-86$ years).

There are surprisingly few injuries for the number of falls, and this phenomenon has been observed in other neurological conditions affecting a younger range of people who fall frequently, e.g. multiple sclerosis (Gunn, Creanor, Haas, Marsden, \& Freeman, 2014). This may be due to less physical fragility and perhaps some learned saving responses to falls. The latter has not been explored and the pattern of responses may be an interesting area to study further.

As a common phenomenon, the impact of falls can be far reaching. Reduced balance confidence relates to falls in people with CMT (1), and people may start to limit physical functioning if they are fearful of falling. Interventions to improve balance and reduce the incidence of falls remain an important goal of rehabilitation interventions. Understanding the risks and situations that could precipitate falls can 
be helpful in falls self-management approaches when educating people how to adjust their environment and manage riskier situations proactively.

\section{Study Limitations}

This study presents data on a moderate size cohort for a rare condition, but as the sample was from one specialist centre, it may not be representative of people in different areas or countries. Response bias has been explored and is a clear limitation and has implications for the the accuracy of our suggested falls frequency. Another issue for consideration is that the Falls Events Questionnaire asks for recollection of the three last falls events. Depending on the length of time that has occured, there could be issues with recolletion of the details of the event, for example where a person was and what they think may have happened. To address this, prospective study designs are required using methods where people can report falls as they happen, and we are currently exploring this in a laboratory based study investigating the links between falls and balance impairment (Ramdharry et al., 2015).

\section{Conclusion}

People with CMT report a high frequency of falls, compared to literature on falls in community dwelling adults, and frequent near falls. These events most commonly occur when walking in the home. There are indications that muscle weakness is a key contributor. Further investigation is required to explore the clinical and postural predictors of falls risk in this group. 


\begin{tabular}{|c|c|}
\hline $\begin{array}{l}\text { For the last three falls that } \\
\text { you remember, try to recall } \\
\text { the following information: }\end{array}$ & $\begin{array}{l}\text { 1. Where were you when you fell? } \\
\text { 2. What were you doing or trying to do at the time? } \\
\text { 3. What do you think caused you to fall? } \\
\text { 4. Do you remember how you landed? } \\
\text { 5. Were you injured? }\end{array}$ \\
\hline $\begin{array}{l}\text { For the last three near falls } \\
\text { that you remember, try to } \\
\text { recall the following } \\
\text { information: }\end{array}$ & $\begin{array}{l}\text { 1. What sort of things were you doing when you } \\
\text { nearly fell? } \\
\text { 2. Why do you think you nearly fell? } \\
\text { 3. How did you save yourself from falling? }\end{array}$ \\
\hline
\end{tabular}

Table 1: Questions on the circumstances of falls and near falls from the Falls Events Questionnaire (Ashburn et al., 2008). Open text boxes were available for text in the administered version.

\begin{tabular}{|l|c|c|}
\hline & $\begin{array}{c}\text { Survey } \\
\text { responders }\end{array}$ & Non-responders \\
\hline Mean age (SD) & $50.31(16.63)^{\star}$ & $43.26(15.47)^{*}$ \\
\hline Age range & $19-86$ & $17-83$ \\
\hline Sex (\% male) & $51.4 \%$ & $53.8 \%$ \\
\hline CMT type 1 & $50.5 \%$ & $45.5 \%$ \\
\hline CMT type 2 & $24.3 \%$ & $22.06 \%$ \\
\hline $\begin{array}{l}\text { Distal hereditary motor } \\
\text { neuropathy }\end{array}$ & $7.5 \%$ & $7.6 \%$ \\
\hline $\begin{array}{l}\text { Hereditary sensory motor } \\
\text { neuropathy }\end{array}$ & $12.2 \%$ & $13.8 \%$ \\
\hline CMT type X & $2.8 \%$ & $8.9 \%$ \\
\hline Intermediate CMT & $2.8 \%$ & $2.1 \%$ \\
\hline
\end{tabular}

Table 2: Demographic details of surveys responders and those who didn't respond. * signifies a significant difference $(p<0.05)$. SD: standard deviation. 
Physiotherapy Research International: Manuscript accepted 14/11/2017
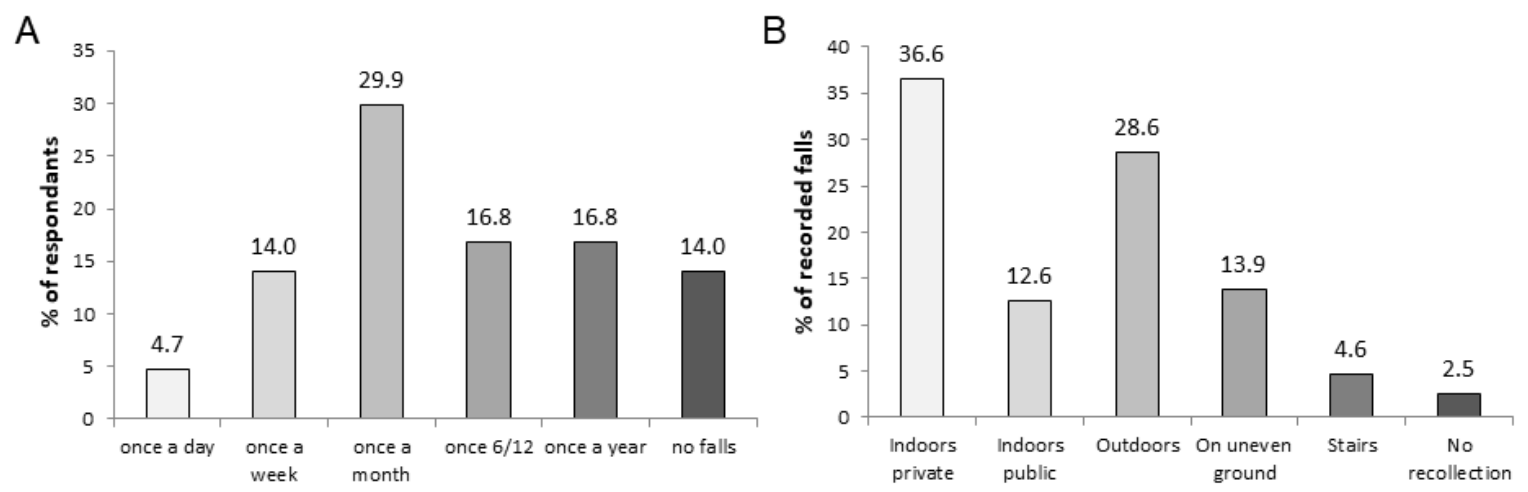

C

D
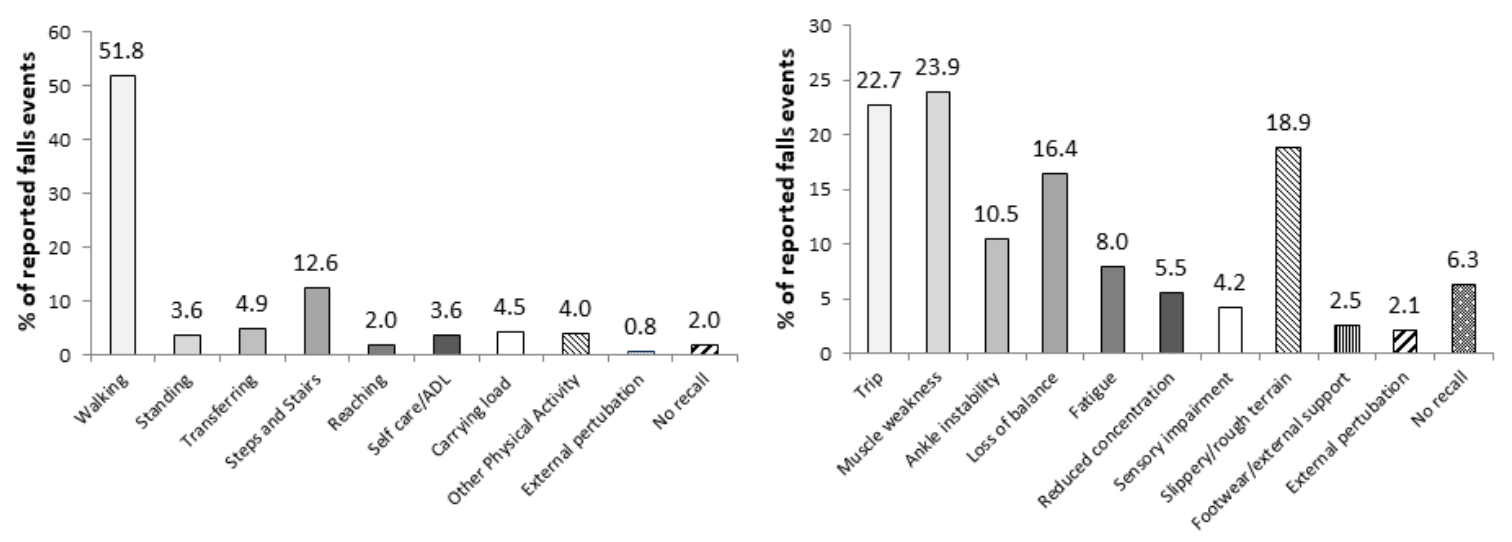

Figure 1: A Frequency of falls events; B Where falls occurred; C Activity when falls occurred; D Perceived cause of fall 
Physiotherapy Research International: Manuscript accepted 14/11/2017

A

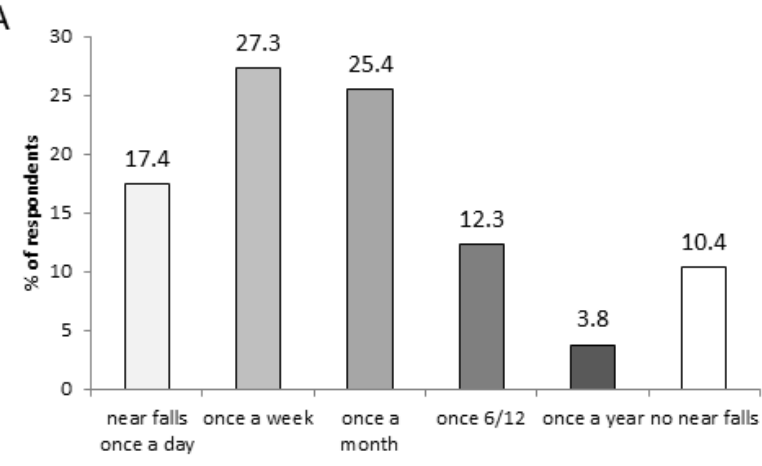

B

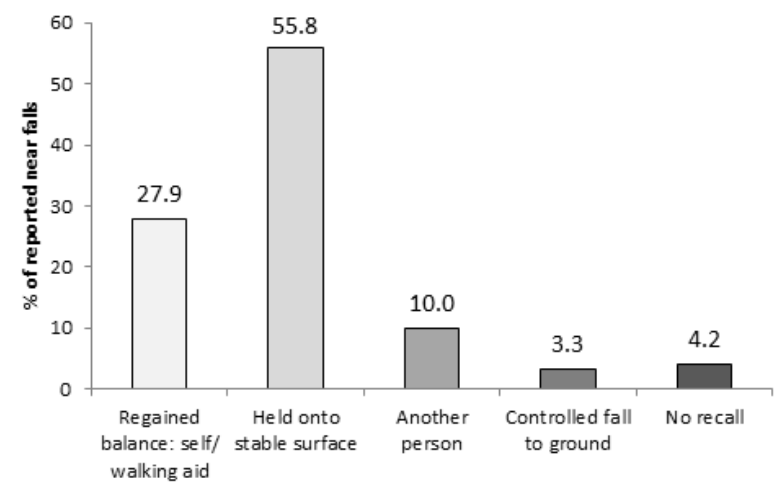

Figure 2: A Frequency of near falls; $\mathbf{B}$ What prevented a fall to the ground 
Physiotherapy Research International: Manuscript accepted 14/11/2017

\section{References}

Ashburn, A., Stack, E., Ballinger, C., Fazakarley, L., \& Fitton, C. (2008). The circumstances of falls among people with Parkinson's disease and the use of Falls Diaries to facilitate reporting. Disability and Rehabilitation, 30(16), 12051212. https://doi.org/10.1080/09638280701828930

Barreto, L. C. L. S., Oliveira, F. S., Nunes, P. S., de França Costa, I. M. P., Garcez, C. A., Goes, G. M., ... de Souza Araújo, A. A. (2016). Epidemiologic Study of Charcot-Marie-Tooth Disease: A Systematic Review. Neuroepidemiology, 46(3), 157-165. https://doi.org/10.1159/000443706

Burns, J., Ryan, M. M., \& Ouvrier, R. A. (2009). Evolution of foot and ankle manifestations in children with CMT1A. Muscle \& Nerve, 39(2), 158-166. https://doi.org/10.1002/mus.21140

Eichinger, K., Odrzywolski, K., Sowden, J., \& Herrmann, D. N. (2016). Patient Reported Falls and Balance Confidence in Individuals with Charcot-Marie-Tooth Disease. Journal of Neuromuscular Diseases, 3(2), 289-292. https://doi.org/10.3233/JND-160159

Gunn, H., Creanor, S., Haas, B., Marsden, J., \& Freeman, J. (2014). Frequency, characteristics, and consequences of falls in multiple sclerosis: findings from a cohort study. Archives of Physical Medicine and Rehabilitation, 95(3), 538-545. https://doi.org/10.1016/j.apmr.2013.08.244

Handsaker, J. C., Brown, S. J., Bowling, F. L., Maganaris, C. N., Boulton, A. J. M., \& Reeves, N. D. (2016). Resistance exercise training increases lower limb speed of strength generation during stair ascent and descent in people with diabetic peripheral neuropathy. Diabetic Medicine, 33(1), 97-104. https://doi.org/10.1111/dme.12841 
Hiscock, A., Dewar, L., Parton, M., Machado, P., Hanna, M., \& Ramdharry, G. (2014). Frequency and circumstances of falls in people with inclusion body myositis: a questionnaire survey to explore falls management and physiotherapy provision. Physiotherapy, 100(1), 61-65. https://doi.org/10.1016/j.physio.2013.06.002

Hyndman, D., Ashburn, A., \& Stack, E. (2002). Fall events among people with stroke living in the community: circumstances of falls and characteristics of fallers. Archives of Physical Medicine and Rehabilitation, 83(2), 165-170. Retrieved from http://www.ncbi.nlm.nih.gov/pubmed/11833018

Kim, B. J., \& Robinson, C. J. (2006). Effects of diabetic neuropathy on body sway and slip perturbation detection in older population. International Journal of Occupational Safety and Ergonomics, 12(3), 241-254.

https://doi.org/10.1080/10803548.2006.11076686

Nardone, A., Grasso, M., \& Schieppati, M. (2006). Balance control in peripheral neuropathy: are patients equally unstable under static and dynamic conditions? Gait \& Posture, 23(3), 364-373. https://doi.org/10.1016/j.gaitpost.2005.04.002 Nardone, A., Tarantola, J., Miscio, G., Pisano, F., Schenone, A., \& Schieppati, M. (2000). Loss of large-diameter spindle afferent fibres is not detrimental to the control of body sway during upright stance: evidence from neuropathy. Experimental Brain Research, 135(2), 155-162. https://doi.org/10.1007/s002210000513

Pieterse, A. J., Luttikhold, T. B., de Laat, K., Bloem, B. R., van Engelen, B. G., \& Munneke, M. (2006). Falls in patients with neuromuscular disorders. Journal of the Neurological Sciences, 251(1-2), 87-90. https://doi.org/10.1016/j.jns.2006.09.008 
Ramdharry, G., Dudziec, M., Tropman, D., Dewar, E., Wallace, A., Laura, M., ... Reilly, M. (2015). Exploring the causes of falls and balance impairments in people with Charcot-Marie Tooth disease. Physiotherapy, 101, e1255. https://doi.org/10.1016/j.physio.2015.03.1159

Rossor, A. M., Evans, M. R. B., \& Reilly, M. M. (2015). A practical approach to the genetic neuropathies. Practical Neurology, 15(3), 187-198.

https://doi.org/10.1136/practneurol-2015-001095

Stack, E., \& Ashburn, A. (1999). Fall events described by people with Parkinson's disease: implications for clinical interviewing and the research agenda. Physiotherapy Research International: The Journal for Researchers and Clinicians in Physical Therapy, 4(3), 190-200. Retrieved from http://www.ncbi.nlm.nih.gov/pubmed/10581625

Talbot, L. A., Musiol, R. J., Witham, E. K., \& Metter, E. J. (2005). Falls in young, middle-aged and older community dwelling adults: perceived cause, environmental factors and injury. BMC Public Health, 5, 86. https://doi.org/10.1186/1471-2458-5-86

Tozza, S., Aceto, M. G., Pisciotta, C., Bruzzese, D., lodice, R., Santoro, L., \& Manganelli, F. (2016). Postural instability in Charcot-Marie-Tooth $1 \mathrm{~A}$ disease. Gait \& Posture, 49, 353-357. https://doi.org/10.1016/j.gaitpost.2016.07.183 van der Linden, M. H., van der Linden, S. C., Hendricks, H. T., van Engelen, B. G. M., \& Geurts, A. C. H. (2010). Postural instability in Charcot-Marie-Tooth type $1 \mathrm{~A}$ patients is strongly associated with reduced somatosensation. Gait \& Posture, 31(4), 483-488. https://doi.org/10.1016/j.gaitpost.2010.02.005 Wiles, C. M., Busse, M. E., Sampson, C. M., Rogers, M. T., Fenton-May, J., \& van Deursen, R. (2006). Falls and stumbles in myotonic dystrophy. Journal of 
Physiotherapy Research International: Manuscript accepted 14/11/2017

Neurology, Neurosurgery, and Psychiatry, 77(3), 393-396.

https://doi.org/10.1136/jnnp.2005.066258 